\title{
Scrapie in Swine: a Diagnostic Challenge
}

\author{
Justin J. Greenlee', Robert A. Kunkle ${ }^{1}$, Jodi D. Smith ${ }^{1}$, and M. Heather West Greenlee ${ }^{2}$ \\ ${ }^{1}$ Virus and Prion Research Unit, National Animal Disease Center, ARS, USDA, Ames, lowa, USA \\ ${ }^{2}$ Iowa State University, Ames, lowa, USA
}

A naturally occurring prion disease has not been recognized in swine, but the agent of bovine spongiform encephalopathy does transmit to swine by experimental routes. Swine are thought to have a robust species barrier when exposed to the naturally occurring prion diseases of other species, but the susceptibility of swine to the agent of sheep scrapie has not been thoroughly tested. We conducted this experiment to test the susceptibility of swine to U.S. scrapie isolates by intracranial and oral inoculation. Scrapie inoculum was a pooled $10 \%(\mathrm{w} / \mathrm{v})$ homogenate derived from the brains of clinically ill sheep from the $4^{\text {th }}$ passage of a serial passage study of the U.S scrapie agent (No. 13-7) through susceptible sheep (homozygous ARQ at prion protein residues 136,154, and 171, respectively). Pigs were inoculated intracranially $(\mathrm{n}=19)$ with a single $0.75 \mathrm{~mL}$ dose or orally $(\mathrm{n}=24)$ with $15 \mathrm{~mL}$ repeated on 4 consecutive days. Necropsies were done on a subset of animals at approximately six months post inoculation (PI): the time the pigs were expected to reach market weight. Remaining pigs were maintained and monitored for clinical signs of transmissible spongiform encephalopathies (TSE) until study termination at 80 months PI or when removed due to intercurrent disease (primarily lameness). Brain samples were examined by immunohistochemistry (IHC), western blot (WB), enzyme immunoassay (EIA), and for a subset of pigs in each inoculation group, bioassay in mice expressing porcine prion protein. At six-months PI, no evidence of scrapie infection was noted by any diagnostic method. However, at 51 months of incubation or greater, 5 animals were positive by one or more methods: IHC $(n=4), W B(n=3)$, or EIA $(n=4)$. Furthermore, positive bioassay results were obtained from all inoculated groups (oral and intracranial; market weight and end of study) suggesting that swine are potential hosts for the agent of scrapie.

Key words: prion, scrapie, swine, transmissible spongiform encephalopathy (6)

Prion diseases are a family of fatal neurodegenerative diseases that include scrapie of sheep and goats, bovine spongiform encephalopathy (BSE), chronic wasting disease of cervids, and Creutzfeldt-Jakob disease of humans. Transmission of prion diseases amongst animals of the same species can be efficient, but there is often a significant barrier to transmission between species ${ }^{1,2)}$. A natural prion disease of pigs has not been described, not even in the UK where pigs were likely to have been exposed to BSE contaminated feed prior to $1996^{3)}$.

The ability of a given prion agent to infect some species and not others is referred to as species barrier ${ }^{4-6}$ ). The species barrier can manifest as lack of disease susceptibility, incomplete attack rates, or prolonged incubation periods. An

Received: 22 July 2016; Accepted: 5 October 2016; Published online: 7 December 2016

Corresponding author: Justin J. Greenlee, Virus and Prion Research Unit, National Animal Disease Center, ARS, USDA, 1920

Dayton Ave. Ames, Iowa, 50010 USA (justin.greenlee@ars.usda.gov)

The contents of this article reflect solely the view of the author(s).

Conflict of interest statement: The authors had no conflicts of interest to declare in this article.

This paper was presented at the Animal Prion Diseases Workshop "Updated Diagnosis and Epidemiology of Animal Prion Diseases for Food Safety and Security" supported by the OECD Co-operative Research Programme.

Abbreviations: BSE: bovine spongiform encephalopathy; EIA: enzyme immunoassay; IHC: immunohistochemistry; PI: post inoculation; PrP: prion protein; PrPSc: abnormal prion protein; TSE: transmissible spongiform encephalopathies; WB: western blot 
initial passage is usually not efficient between species, but subsequent passages can lead to stabilization of disease in a new species ${ }^{7}$. The major influence on species barrier is amino acid sequence differences between the donor and recipient hosts ${ }^{6,8)}$ and the effect on prion protein structure and folding ${ }^{9}$.

The susceptibility and incubation periods of prion disease in an individual are highly dependent on the amino acid sequence of the prion protein in mice ${ }^{10)}$, sheep ${ }^{11-13)}$, cervids ${ }^{14,15)}$, and humans ${ }^{16)}$. However, compared to sheep, cervids, and humans, the porcine prion protein $(\mathrm{PrP})$ is highly homogenous ${ }^{17,18)}$ with only four known single nucleotide polymorphisms (G11A, G615C, G684A, T726G) one of which (G615C) that results in a serine to asparagine substitution at codon 4 that is not part of the mature prion protein ${ }^{19}$. As compared to cattle, pigs have 5 unique amino acids that appear in the prion protein sequence of the globular domain and 4 of these appear in helix $3^{20)}$. While epidemiologic evidence would suggest pigs are not susceptible to prion disease, in vitro assays demonstrate that recombinant porcine PrP converts to amyloid fibrils faster than human or bovine sequences ${ }^{21)}$.

Several experimental studies have been conducted to test the susceptibility of pigs to prion diseases. The agent of BSE transmitted to pigs after multiple-route (concurrent intracranial, intravenous, and intraperitoneal) parenteral inoculation with an incubation period of 17-38 months and resulted in severe neuropil vacuolation and abnormal prion protein $\left(\mathrm{PrP}^{\mathrm{Sc}}\right)$ accumulation in the brain ${ }^{3)}$. Further, infectivity was demonstrated in brain, spinal cord, stomach, small intestine, and pancreas by bioassay in C57BLJ6 mice ${ }^{22}$. However, attempts to transmit BSE to pigs after oral dosing with up to $1.2 \mathrm{~kg}$ of brain material from infected cattle was unsuccessful ${ }^{23}$. Studies utilizing transgenic mice expressing the porcine prion protein suggest that initial low dose exposure to BSE prions may result in a subclinical infection that results in a high attack rate and shortened incubation periods on second passage ${ }^{20)}$.

Piglets exposed orally to brain material from scrapie-infected sheep from the UK lacked any evidence of disease and bioassay of tissues from these pigs failed to reveal infectivity in tissues ${ }^{23}$. However, mice expressing porcine $\operatorname{PrP}$ are susceptible to atypical (Nor-98) scrapie with a low attack rate that adapts to $100 \%$ attack rate with a rapid incubation on subsequent passages ${ }^{24)}$, similar to the adaptation that was observed in experiments that were conducted with BSE ${ }^{20,24)}$. Interestingly, sheep passaged BSE transmits more efficiently to pigs than BSE from cattle and was associated with $\operatorname{PrP}^{\mathrm{Sc}}$ in variety of peripheral tissues ${ }^{25)}$.

We conducted a study to determine if swine were susceptible to an isolate of the US scrapie agent by either the intracranial or oral route. Initially, we used transgenic mice expressing porcine prion protein (PoPrP-Tg002) to test their susceptibility to the agent of sheep scrapie. No mice in this study developed clinical signs before the end of the experiment (700 days), but 5/30 tested positive by enzyme immunoassay (EIA; BSE-Scrapie Antigen Test Kit, IDEXX, Westbrook, ME). For the swine study, weaned piglets were inoculated with a $10 \%(\mathrm{w} / \mathrm{v})$ homogenate made from the brains of clinically ill sheep from the $4^{\text {th }}$ passage of a serial passage study of the U.S scrapie agent (No. 13-7) through sheep homozygous ARQ at prion protein residues 136,154 , and 171 , respectively ${ }^{26}$. Intracranial inoculations $\left.{ }^{27}\right)(\mathrm{n}=19)$ were with a single $0.75 \mathrm{~mL}$ dose of homogenate. Oral inoculations $(\mathrm{n}=24)$ were $15 \mathrm{~mL}$ doses repeated on 4 consecutive days. Necropsies were done on a subset of animals at approximately six months post inoculation (PI): the time the pigs were expected to reach market weight. Remaining pigs were maintained and monitored for clinical signs of transmissible spongiform encephalopathies (TSE) until study termination at 80 months PI or when removed due to intercurrent disease. Brain samples were examined by immunohistochemistry $(\mathrm{IHC})^{28)}$, western blot (WB) ${ }^{12}$, enzyme immunoassay $(E I A)^{29)}$, and for a subset of pigs in each inoculation group, bioassay in mice expressing porcine PrP.

All pigs examined at market weight tested negative by traditional diagnostic methods. However, 5/10 aged pigs that were necropsied at 51 months of age or later tested positive using immunohistochemistry (IHC; $n=4)$ ), western blot (WB; $n=3)$, and/or EIA ( $\mathrm{n}=4)$. In all hematoxylin and eosin stained slides examined by light microscopy, there was no evidence of spongiform encephalopathy beyond that present in negative control pigs. Examination of slides stained by an immunohistochemical method with monoclonal antibody L42 that targets to amino acids 145-163 of the ovine prion protein sequence ${ }^{30)}$ demonstrated immunoreactivity that was largely confined within neurons (Fig. 1) and was present in hippocampus, cerebellum, thalamus, brainstem, and spinal cord. Findings from HE and IHC were similar to scrapie in cattle where spongiform change was not noted and IHC positives had prominent intraneuronal labeling ${ }^{31}$. In pigs that were WB positive, the molecular profile was distinct from the original scrapie inoculum in that the nonglycosylated band migrated lower than sheep scrapie and that the profile had a most prominent monoglycosylated rather than diglycosylated band (Fig. 2).

One pig from each inoculation group was bioassayed in PoPrP-Tg002 mice. Bioassay results were determined by EIA. Positive results were obtained from the market weight pigs that were orally $(5 / 29)$ or intracranially $(2 / 27)$ inoculated. The sample that was selected from the orally inoculated aged pig (incubation period $=50$ months) also had a low number of positive results (2/24) in mouse bioassay. Interestingly, the aged pigs from the intracranially inoculated pigs that were IHC, WB, and/or EIA positive that were selected for bioassay yielded 0/29 and 0/30 positive samples, which 


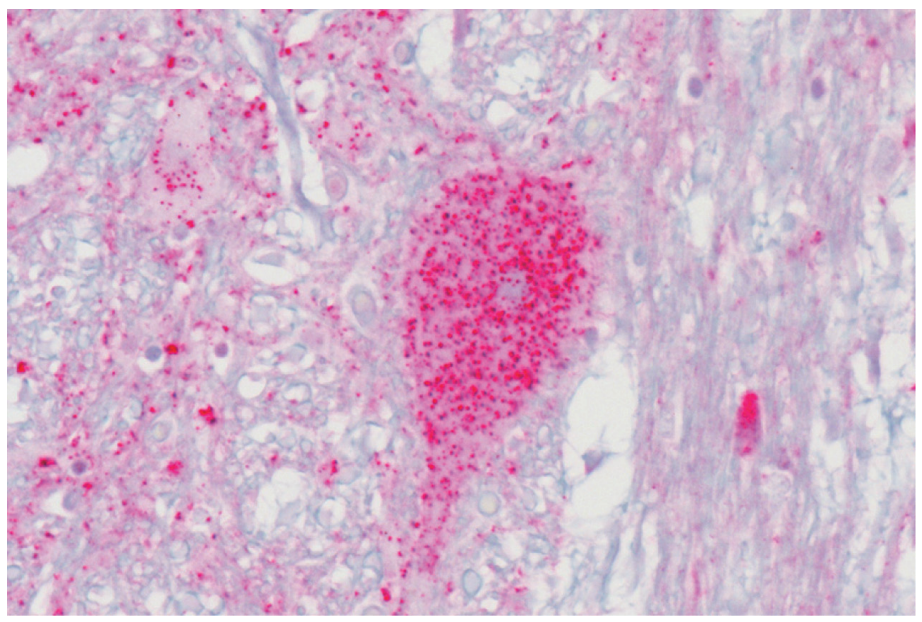

Fig. 1. Immunoreactivity (red) in central nervous system tissues of pigs with scrapie is predominantly intraneuronal. High magnification of the brainstem at the level of the obex with intraneuronal immunoreactivity after staining with an automated protocol using monoclonal antibody L42.

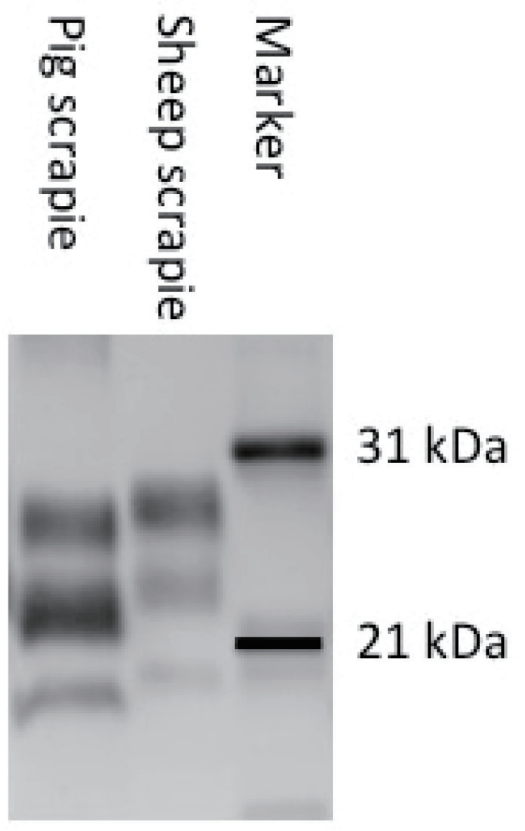

Fig. 2. Western blot analysis demonstrating unique $\operatorname{PrP}^{\mathrm{Sc}}$ profile in pigs with scrapie. The positive sample from a pig inoculated with the agent of scrapie has a prominent monoglycosylated band and lower migration relative to the sheep scrapie inoculum. Blot developed with monoclonal antibody L42.

was unexpected. This interesting result contrasted those of BSE samples where second passage results in a $100 \%$ attack rate with a relatively short incubation period ${ }^{20,24}$. Of great interest are the mice that tested ELISA positive after bioassay of brain material from an orally inoculated pig that was examined at market weight. These mice were collected at the end of the mouse study that was scheduled to last for 700 days post-inoculation. The positive mice had low EIA optical density scores. No vacuolar change was noted on sections available for lesion profiling. A second passage from a positive mouse with a positive EIA was attempted in mice expressing porcine prion protein (PoPRP-Tg002) or mice expressing sheep prion protein (Tg338). The second passage in PoPRP-Tg002 mice is ongoing, but passage to Tg338 mice resulted in 16/20 positive mice. This work demonstrates that pigs are susceptible to the US scrapie agent by oral and intracranial inoculation. Aged animals inoculated intracranially were detectable by traditional diagnostic methods, however, orally 
exposed aged or market weight animals, while positive by bioassay were not detected by any standard diagnostic technique. Further, no animals demonstrated clinical signs of disease or had spongiform change in their brains.

Pigs were exposed to the agent of BSE in contaminated meat and bone meal in many European countries, but no naturally occurring cases have been described and surveys of meat and bone meal fed pigs failed to demonstrate any evidence of TSE ${ }^{32}$. Pigs challenged orally with BSE failed to develop evidence of infection ${ }^{33)}$ despite observation for up to seven years ${ }^{22}$. These previously published studies along with results of the current study suggest that swine are capable of harboring a prion disease, although epidemiologic evidence is not in support of this occurring under production conditions.

We have demonstrated that swine are susceptible to the agent of sheep scrapie. While no pigs examined at market weight were positive by traditional diagnostic methods, there were 5 aged pigs with positive IHC, WB, and/or ELISA from brain tissue. These pigs did not have definitive clinical illness or spongiform change during the course of this experiment. Positive bioassay results from the brains of market weight pigs suggest that even orally inoculated pigs do harbor a low level of infectivity. If scrapie were to occur in pigs, it would represent a significant diagnostic challenge because of long incubation periods, failure of pigs to develop clinical signs, and the inability of traditional diagnostic methods to detect infected animals early in the course of disease.

\section{Acknowledgement}

The authors thank Martha Church, Kevin Hassall, Joe Lesan, Leisa Mandell, and Trudy Tatum for providing technical support to this project. Dr. Glenn Telling produced the PoPrP-Tg002 mice funded through specific cooperative agreement 58-3625-7-649 with the University of Kentucky. The positive control sample from a pig with bovine spongiform encephalopathy was a gift from the APHA Biological Archive. We thank Dr. Hubert Laude for permission to use Tg338 mice. Mention of trade names or commercial products in this article is solely for the purpose of providing specific information and does not imply recommendation or endorsement by the US Department of Agriculture. USDA is an equal opportunity provider and employer.

\section{References}

1. Pattison IH, Jones KM. Modification of a strain of mouse-adapted scrapie by passage through rats. Res Vet Sci. 1968; 9: 408-410. [Medline]

2. Kocisko DA, Priola SA, Raymond GJ, Chesebro B, Lansbury PT Jr, Caughey B. Species specificity in the cell-free conversion of prion protein to protease-resistant forms: a model for the scrapie species barrier. Proc Natl Acad Sci U S A. 1995; 92: 3923-3927. [Medline]

3. Ryder SJ, Hawkins SA, Dawson M, Wells GA. The neuropathology of experimental bovine spongiform encephalopathy in the pig. J Comp Pathol. 2000; 122: 131-143. [Medline]

4. Hill AF, Collinge J. Strain variations and species barriers. Contrib Microbiol. 2001; 7: 48-57. [Medline]

5. Hill AF, Joiner S, Linehan J, Desbruslais M, Lantos PL, Collinge J. Species-barrier-independent prion replication in apparently resistant species. Proc Natl Acad Sci U S A. 2000; 97: 10248-10253. [Medline]

6. Moore RA, Vorberg I, Priola SA. Species barriers in prion diseases—brief review. Arch Virol Suppl. 2005; 19: 187-202. [Medline]

7. Hill AF, Collinge J. Prion strains and species barriers. Contrib Microbiol. 2004; 11: 33-49. [Medline]

8. Scott M, Groth D, Foster D, et al. Propagation of prions with artificial properties in transgenic mice expressing chimeric PrP genes. Cell. 1993; 73: 979-988. [Medline]

9. Vanik DL, Surewicz KA, Surewicz WK. Molecular basis of barriers for interspecies transmissibility of mammalian prions. Mol Cell. 2004; 14: 139-145. [Medline]

10. Hunter N, Foster JD, Hope J. Natural scrapie in British sheep: breeds, ages and PrP gene polymorphisms. Vet Rec. 1992; 130: 389-392. [Medline]

11. Goldmann W, Hunter N, Smith G, Foster J, Hope J. PrP genotype and agent effects in scrapie: change in allelic interaction with different isolates of agent in sheep, a natural host of scrapie. J Gen Virol. 1994; 75: 989-995. [Medline]

12. Greenlee JJ, Zhang X, Nicholson EM, Kunkle RA, Hamir AN. Prolonged incubation time in sheep with prion protein containing lysine at position 171. J Vet Diagn Invest. 2012; 24: 554-558. [Medline]

13. Hunter N, Goldmann W, Foster JD, Cairns D, Smith G. Natural scrapie and PrP genotype: case-control studies in British sheep. Vet Rec. 1997; 141: 137-140. [Medline]

14. O’Rourke K, Spraker T, Zhuang D, Greenlee J, Gidlewski T, Hamir A. Elk with a long incubation prion disease phenotype have a unique PrPd profile. Cellular. Molecular and Developmental Neuroscience. 2007; 18: 1935-1938. 
15. Johnson C, Johnson J, Vanderloo JP, Keane D, Aiken JM, McKenzie D. Prion protein polymorphisms in white-tailed deer influence susceptibility to chronic wasting disease. J Gen Virol. 2006; 87: 2109-2114. [Medline]

16. Collinge J, Palmer MS, Dryden AJ. Genetic predisposition to iatrogenic Creutzfeldt-Jakob disease. Lancet. 1991; 337: 14411442. [Medline]

17. Martin T, Hughes S, Hughes K, Dawson M. Direct sequencing of PCR amplified pig PrP genes. Biochim Biophys Acta. 1995; 1270: 211-214. [Medline]

18. Lipp O, Ritzmann M, Kixmöller M, Heinritzi K, Hensel A, Truyen U. Homogeneity of the prion protein gene in various European and Asian pig breeds. J Vet Med B Infect Dis Vet Public Health. 2004; 51: 97-98. [Medline]

19. Meng L, Zhao D, Liu H, Yang J, Ning Z. Single nucleotide polymorphisms of the prion protein gene $(P R N P)$ in Chinese pig breeds. Xenotransplantation. 2005; 12: 324-326. [Medline]

20. Castilla J, Gutiérrez-Adán A, Brun A, et al. Subclinical bovine spongiform encephalopathy infection in transgenic mice expressing porcine prion protein. J Neurosci. 2004; 24: 5063-5069. [Medline]

21. Hammarström P, Nyström S. Porcine prion protein amyloid. Prion. 2015; 9: 266-277. [Medline]

22. Wells GA, Hawkins SA, Austin AR, et al. Studies of the transmissibility of the agent of bovine spongiform encephalopathy to pigs. J Gen Virol. 2003; 84: 1021-1031. [Medline]

23. Matthews D, Cooke BC. The potential for transmissible spongiform encephalopathies in non-ruminant livestock and fish. Rev Sci Tech. 2003; 22: 283-296. [Medline]

24. Espinosa JC, Herva ME, Andréoletti O, et al. Transgenic mice expressing porcine prion protein resistant to classical scrapie but susceptible to sheep bovine spongiform encephalopathy and atypical scrapie. Emerg Infect Dis. 2009; 15: 1214-1221. [Medline]

25. Hedman C, Bolea R, Marín B, et al. Transmission of sheep-bovine spongiform encephalopathy to pigs. Vet Res. 2016 ; 47: 14. [Medline]

26. Hamir AN, Kunkle RA, Richt JA, Greenlee JJ, Miller JM. Serial passage of sheep scrapie inoculum in Suffolk sheep. Vet Pathol. 2009; 46: 39-44. [Medline]

27. Hamir AN, Kunkle RA, Richt JA, Miller JM, Cutlip RC, Jenny AL. Experimental transmission of sheep scrapie by intracerebral and oral routes to genetically susceptible Suffolk sheep in the United States. J Vet Diagn Invest. 2005; 17: 3-9. [Medline]

28. Greenlee JJ, Smith JD, Kunkle RA. White-tailed deer are susceptible to the agent of sheep scrapie by intracerebral inoculation. Vet Res. 2011; 42: 107. [Medline]

29. Smith JD, Greenlee JJ. Detection of misfolded prion protein in retina samples of sheep and cattle by use of a commercially available enzyme immunoassay. Am J Vet Res. 2014; 75: 268-272. [Medline]

30. Hardt M, Baron T, Groschup MH. A comparative study of immunohistochemical methods for detecting abnormal prion protein with monoclonal and polyclonal antibodies. J Comp Pathol. 2000; 122: 43-53. [Medline]

31. Cutlip RC, Miller JM, Race RE, et al. Intracerebral transmission of scrapie to cattle. J Infect Dis. 1994; 169: 814-820. [Medline]

32. Jahns H, Callanan JJ, Sammin DJ, McElroy MC, Bassett HF. Survey for transmissible spongiform encephalopathies in Irish pigs fed meat and bone meal. Vet Rec. 2006; 159: 137-142. [Medline]

33. Dawson M, Wells GA, Parker BN, Scott AC. Primary parenteral transmission of bovine spongiform encephalopathy to the pig. Vet Rec. 1990; 127: 338. [Medline] 